\title{
IMPACTO DA IDADE AO PARTO NO DESEMPENHO PRODUTIVO E REPRODUTIVO EM VACAS HOLANDESAS PRIMÍPARAS
}

\author{
(Impact of age at calving on lactation and reproduction performance at the \\ first-parity holsteins)
}

\author{
GREBOGI, A. ${ }^{1}$; OSTRENSKY, A. ${ }^{1}$; POHL, F.'; ALMEIDA, R. ${ }^{2}$; WEISS, R.R. ${ }^{2}$; KOZICKI, L.E. ${ }^{1}$; \\ BREDA J.C. ${ }^{3}$; GIACOMELI A.M. ${ }^{3}$ \\ 1Pontifícia Universidade Católica do Paraná \\ ¿Universidade Federal do Paraná \\ ${ }^{3}$ Acadêmicos do Curso de Medicina Veterinária da PUCPR
}

\begin{abstract}
RESUMO - Com o objetivo de determinar o impacto da idade ao primeiro parto (IPP) no desempenho produtivo e reprodutivo de vacas leiteiras, 32 noviIhas Holandesas foram distribuídas em dois grupos de acordo com a IPP: 16 novilhas foram classificadas como "Novas", com IPP inferior a 700 dias e 16 novilhas foram classificadas como "Velhas", com IPP superior a 700 dias. Dados de desempenho produtivo e reprodutivo foram analisados por análise de variância usando o procedimento GLM do SAS. Novilhas de primeiro parto que pariram antes dos 700 dias de idade apresentaram menor produção de leite $(P<0,05)$ (novas-9.900 vs. 11.618 kgvelhas), menor produção de gordura $(P<0,05)(373$ vs. $425 \mathrm{~kg})$ e menor produção de proteína $(P<0,05)$ ( 279 vs. $307 \mathrm{~kg}$ ) do que novilhas que pariram após os 700 dias de idade. Os teores de gordura e proteína no leite não variaram significativamente entre os dois grupos de primíparas: $3,80 \%$ vs. $3,96 \%$ de gordura e $2,81 \%$ vs. $2,81 \%$ de proteína, respectivamente para Novas e Velhas. Relativamente aos dados de desempenho reprodutivo, novilhas que pariram antes dos 23 meses de idade, apresentaram melhores índices reprodutivos $(P<0,05)$ do que novilhas que pariram mais tarde, isto é, após os 23 meses de idade ou seja: houve menor número de dias entre o parto e o $1^{\circ}$ cio (48,9 vs. 70,4 dias), menor período de serviço $(69,8$ vs. 110,2 dias) e menor intervalo entre partos (359,2 vs. 390,1 dias). Palavras-Chave: Idade ao primeiro parto; novilha raça holandesa; produção de leite; reprodução
\end{abstract}

ABSTRACT - The aim of this study was to determine the impact of age at first calving (AFC) on lactation and reproduction performance in dairy cows. Thirtytwo first-parity Holsteins were distributed in two groups by AFC: 16 first-parity females were named as "Younger", with AFC lower than 700 days, and
16 were classified as "Older", with AFC above 700 days. Lactation and reproduction data were analyzed using GLM procedure from SAS. Firstlactation cows that calved before 700 days of age displayead lower $(P<0,05)$ milk yields $(9,900$ vs. $10,874 \mathrm{~kg})$, lower $(P<0,05) 3,5 \%$ fat-corrected milk yields $(10,341$ vs. $11,618 \mathrm{~kg})$, lower $(P<0,05)$ fat yields ( 373 vs. $425 \mathrm{~kg}$ ), and lower $(P<0,05)$ protein yields ( 279 vs. $307 \mathrm{~kg}$ ) than first-parity Holsteins that calved after 700 days of age. There were no differences between the two groups of AFC for fat and protein contents: $3,80 \%$ vs. $3,96 \%$ fat and $2,81 \%$ vs. $2,81 \%$ protein, respectively for Younger and Older females. Reproduction results showed that first-parity cows that calved earlier, before 23 months of age, had better $(P<0,05)$ reproduction performance than primipara cows that calved later, after 23 months of age: lower days in milk at first estrous ( 48,9 vs. 70,4 days), lower days open $(69,8$ vs. 110,2 days), and lower calving interval $(359,2$ vs. 390,1 days).

Key words: Age at first calving; heifer; milk production; reproduction

\section{INTRODUÇÃO}

A idade do primeiro parto (IPP) é um importante fator no custo de criação de novilhas para reposição em rebanhos leiteiros. Segundo relatos de VERCESI FILHO et al. (2000) e CARDOSO et al. (2004) a idade ao primeiro parto constitui característica de elevada importância econômica nos sistemas de produção de leite nos estados de Minas Gerais e São Paulo, respectivamente.

HEINRICHS (1993) sugeriu que a IPP ideal na raça Holandesa para a máxima lucratividade deveria ser de 23 a 24 meses de idade. TOZER e HEINRICHS (2001) observaram que há um decrés- 
cimo de $18 \%$ nos custos, quando a idade ao primeiro parto reduziu-se de 25 para 21 meses. A IPP pode ser reduzida pelo aumento nas taxas de crescimento (VANAMBURG et al., 1998). Estes autores reduziram a IPP para 21,3 meses, com uma taxa de crescimento média de 1,0 kg/dia e observaram uma redução de $5 \%$ a produção de leite comparada com novilhas alimentadas para ganhar 0,6 kg/dia. A redução no desempenho durante a primeira lactação em novilhas sob crescimento acelerado durante o período prépúbere parece estar associada com a redução do tecido secretório mamário (SEJRSEN et al., 2000). Mesmo quando não houve diferenças significativas nas taxas de crescimento pré-puberdade, novilhas que pariram mais cedo (inferior a 23 meses) apresentaram inferiores produções de leite e componentes, taxas de concepção mais baixas e menor retorno econômico do que novilhas que pariram pela primeira vez entre 23 e 24,5 meses. Entretanto, o aumento da IPP além dos 24,5 meses não melhorou a produção e a reprodução, nem tampouco a sanidade de vacas primíparas (ETTEMA e SANTOS, 2004). VERCESI FILHO et al. (2000) constataram que a IPP avançada apresenta um peso econômico negativo, indicando que a seleção deve ser feita para reduzí-la. Em trabaIho realizado por LEITE et al. (2001) a IPP média foi de 37,1 meses com amplitude de 12,3 a 80,1 meses. RIBEIRO et al. (2003) encontraram valores de IPP média de 28 meses, considerada boa, revelando que a IPP está diretamente relacionada à idade e à concepção. WOLFF et al. (2004) igualmente verificaram IPP média de 27,0 meses, significando que as novilhas foram cobertas e tornaram-se prenhes aos 18 meses aproximadamente.

Assim objetivou-se neste estudo, determinar o impacto da IPP em novilhas da raça Holandesa, sobre alguns parâmetros do desenvolvimento produtivo e reprodutivo em um rebanho leiteiro de elevada produtividade no estado do Paraná.

\section{Material e Métodos}

No experimento foram utilizadas 32 novilhas da raça Holandesa preta e branca $(n=32)$ nascidas e criadas no setor de Bovinocultura da Fazenda Experimental Gralha Azul (FEGA), pertencente à Pontifícia Universidade Católica do Paraná (PUCPR), no município de Fazenda Rio Grande, Paraná. Os animais foram distribuídos em dois grupos: G1 - 16 novilhas, as quais foram inseminadas aos $395 \pm 17$ dias (13,0 meses), enquanto 16 novilhas foram inseminadas aos $451 \pm 22$ dias (14,8 meses)

Não houve diferenças significativas $(P>0,10)$ no peso à cobertura (408 vs. $415 \mathrm{~kg}$ ) ou no escore de condição corporal (ECC) à cobertura $(3,59$ vs 3,56$)$ entre os lotes de novilhas inseminadas mais precocemente ou mais tardiamente, respectivamente.
As 32 parturições ocorreram em um período de 30 meses: outubro de 2002 a maio de 2005 . Foram utilizadas somente primíparas que tiveram partos fisiológicos. As novilhas foram classificadas em dois grupos de acordo com a idade ao primeiro parto (IPP): novilhas "Novas", com IPP inferior a 700 dias e novilhas "Velhas", com IPP superior a 700 dias. A média geral da IPP para as 32 novilhas foi 701 dias (ou 23,0 \pm 1,1 meses). As médias da IPP por grupo de novilhas, respectivamente novas e velhas, foram $673 \pm 16$ e $729 \pm 23$ dias.

Após o parto e durante toda a primeira lactação, as primíparas foram alojadas em instalações do tipo free-stall. Dados de produção de leite foram coletados mensalmente, segundo as normas do controle oficial do Programa de Análise de Rebanhos Leiteiros do Paraná (PARLPR). Amostras individuais de ordenhas consecutivas (tarde e manhã seguinte) foram analisadas para determinar as concentrações de gordura e proteína em equipamento automatizado Bentley 2000. Dados de características produtivas foram obtidos a partir das lactações encerradas em 305 dias. Se a primípara apresentasse lactação inferior a 305 dias, a lactação real foi utilizada, já que lactações mais curtas não foram projetadas para 305 dias. Não houve diferença significativa $(P>0,10)$ no período médio de lactação entre os dois grupos: 303 \pm 6 dias para as novilhas que pariram mais cedo e $301 \pm 7$ dias para as que pariram mais tarde.

Dados de desempenho produtivo e reprodutivo foram analisados por análise de variância, usando o procedimento GLM (SAS, 2001), com a inclusão dos efeitos fixos de grupo (baixa ou alta IPP) e de estação do parto e da covariável dias em leite (ou período de lactação). A distribuição das 32 novilhas nas quatro estações de parto foi bastante heterogênea, o que justifica a inclusão deste efeito no modelo. Quinze novilhas pariram no verão, oito no outono, oito na primavera e somente uma no inverno. Resultados são apresentados como médias ajustadas e diferenças entre grupos com $\mathrm{P}<0,01$ ou $\mathrm{P}<0,05$ foram consideradas significativas, enquanto que aquelas com $0,05<\mathrm{P}<0,10$ foram consideradas como tendência.

\section{Resultados e Discussão}

Os resultados obtidos no presente estudo estão expostos nas TABELAS 1 e 2. Ao se confrontar os dois grupos de novilhas ao primeiro parto, observouse que os animais que pariram antes dos 700 dias de idade apresentaram menor $(P<0,05)$ produção de leite $(9.900$ vs. $10.874 \mathrm{~kg})$ e menor $(P<0,05)$ produção de gordura (10.341 vs. $11.618 \mathrm{~kg}$ ) do que novilhas que pariram após 700 dias. Estes resultados são concordantes com os trabalhos de ETTEMA e SANTOS (2004) e VAN AMBURG et al. (1998), os 
quais demonstraram que há redução no volume de leite quando a novilha é inseminada aos 13 meses de idade, ao invés dos tradicionais 14-15 meses.

Animais primíparos que pariram antes dos 700 dias de idade igualmente apresentaram menor $(P<0,05)$ produção de gordura e proteína (373 kg de gordura e $279 \mathrm{~kg}$ de proteína para o grupo das Novas e $425 \mathrm{~kg}$ de gordura e $307 \mathrm{~kg}$ de proteína para o grupo das Velhas), respectivamente. Entretanto, os percentuais de gordura e de proteína no leite não variaram significativamente entre os dois grupos de novilhas ao se verificar $3,80 \%$ vs. $3,96 \%$ de gordura e $2,81 \%$ de proteína, respectivamente. Estes resultados são corroborados pelos relatos de ETTEMA e SANTOS (2004).

Menor produção de leite bem como dos componentes lácteos, devido à redução na IPP podem estar relacionadas com taxas de crescimento aceleradas durante o período pré-púbere, reduzindo a formação de tecido glandular e aumentando a deposição de tecido adiposo na futura glândula mamária (SEJREN et al., 2000). Deve-se ressaltar que neste estudo observou-se tendência de maior taxa de crescimento nas novilhas que pariram mais cedo ou seja: 0,856 $\pm 0,026 \mathrm{~kg} / \mathrm{dia}$ para as novilhas de IPP inferior a 700 dias e 0,808 \pm $0,022 \mathrm{~kg} /$ dia para as novilhas de IPP superior a 700 dias (não significativo).

O motivo que poderia justificar a maior produção de leite e componentes no grupo de novilhas inseminadas mais tarde, seria o maior e o peso corporal dos animais mais velhos, uma vez que o tamanho e peso corporal são fatores que afetam a incidência de distocia e complicações ao parto, afetando consequentemente o desempenho produtivo de vacas leiteiras. No entanto, neste estudo não foram verificadas diferenças significativas relativas ao peso ao primeiro parto ( $612 \pm 16$ vs. $625 \pm 13 \mathrm{~kg}$ ), nem tampouco no ECC ao primeiro parto (3,57 $\pm 0,07$ para ambos os lotes), respectivamente para o grupo de novilhas Novas e Velhas. Por outro lado, verificou-se uma tendência de maior estatura dos animais que pariram mais tarde: $1,45 \pm 0,01$ vs. $1,42 \pm 0,01 \mathrm{~m}$.

Como era esperado, não houve diferenças significativas no tocante ao período de gestação entre os dois grupos: novilhas Novas apresentaram período de gestação de 279,1 \pm 1,5 dias, enquanto que as novilhas Velhas apresentaram período de gestação de $278 \pm 1,3$ dias.

Por outro lado, verificaram-se diferenças significativas $(P<0,05)$ nas demais características reprodutivas. Novilhas que foram inseminadas mais tarde, isto é, aos 14,8 meses, apresentaram índices reprodutivos inferiores aos das novilhas que foram inseminadas aos 13 meses. Deste modo, foram necessários maior número de dias entre o parto e o $1^{\circ}$ cio $(70,4 \pm 8,8$ vs. $48,9 \pm 10,3$ dias), maior número de dias entre o parto e o início de nova gestação (110,2 $\pm 13,7$ vs. $69,8 \pm$ 16,1 dias), maior intervalo entre partos $(390,1 \pm 12,9$ vs. $359,2 \pm 15,1$ dias) e uma tendência de apresentar maior número de serviços por concepção (1,65 $\pm 0,31$ vs. 1,16 $\pm 0,37)$. Estes resultados contrapõem-se aos relatados por ETTEMAe SANTOS (2004) ao verificarem índices reprodutivos inferiores nas novilhas inseminadas mais precocemente. A razão pelo menor desempenho reprodutivo das novilhas mais velhas do que as novas, no presente estudo, está relacionada com a maior produção de leite, uma vez que neste grupo de animais produziu-se $1277 \mathrm{~kg}$ de leite a mais do que as novilhas mais novas. Encontra-se bem esclarecido na literatura o impacto negativo das elevadas produções, em função da mobilização mais intensa das reservas corporais dos animais sobre o desempenho reprodutivo. Enquanto as novilhas mais novas pariram com um ECC de 3,57 e foram inseminadas com um ECC de 3,02, as novilhas mais velhas pariram com um ECC de 3,57 , mas foram inseminadas com um ECC de 2,59. Ou seja, as noviIhas mais velhas perderam 0,43 pontos de ECC a mais que as novilhas mais novas. Assumindo que um ponto de mobilização de ECC representa 368Mcal de Energia Líquida para Lactação (ELI) (NRC, 2001), a perda de 0,43 pontos representaria 158,2 Mcal. Ao se assumir que um litro de leite como ocorreu, com a composição média deste experimento $(3,66 \%$ de gordura e $2,94 \%$ de proteína) tenha um conteúdo energético de 693 kcal (NRC, 2001), estes 158,2 Mcal seriam equivalentes a 228 litros de leite (18\% do incremento na produção).

TABELA 1 - MÉDIAS AJUSTADAS E RESPECTIVOS ERROS PADRÕES DAS PRINCIPAIS CARACTERÍSTICAS PRODUTIVAS DE VACAS HOLANDESAS PRIMÍPARAS DE ACORDO COM AIDADE AO PRIMEIRO PARTO.

\begin{tabular}{lccc}
\hline Características Produtivas & Novas $^{1}$ & Velhas $^{1}$ & $\operatorname{Pr}>\mathrm{F}$ \\
\hline Produção de leite $(\mathrm{kg})$ & $9900 \pm 537$ & $10874 \pm 448$ & 0,0337 \\
Produção de leite corrigida 3,5\%G $(\mathrm{kg})$ & $10341 \pm 629$ & $11618 \pm 525$ & 0,0187 \\
Produção de gordura $(\mathrm{kg})$ & $373 \pm 31$ & $425 \pm 26$ & 0,0472 \\
Porcentagem de gordura (\%) & $3,80 \pm 0,30$ & $3,96 \pm 0,25$ & 0,5056 \\
Produção de proteína $(\mathrm{kg})$ & $279 \pm 13$ & $307 \pm 11$ & 0,0125 \\
Porcentagem de proteína (\%) & $2,81 \pm 0,08$ & $2,81 \pm 0,07$ & 0,9767 \\
\hline
\end{tabular}

${ }^{1}$ Novas $=$ idade ao primeiro parto $<700 \mathrm{~d}$; Velhas $=$ idade ao primeiro parto $>700 \mathrm{~d}$ 
Impacto da idade ao parto no desempenho produtivo e reprodutivo de vacas holandesas ao primeiro parto

\begin{tabular}{|c|c|c|c|}
\hline Características Produtivas & Novas $^{1}$ & Velhas $^{1}$ & $\operatorname{Pr}>\mathrm{F}$ \\
\hline Período de gestação (dias) & $279 \pm 1$ & $278 \pm 1$ & 0,4974 \\
\hline Dias ao primeiro cio (dias) & $49 \pm 10$ & $70 \pm 9$ & 0,0499 \\
\hline Período de serviço (dias) & $70 \pm 16$ & $110 \pm 14$ & 0,0197 \\
\hline Intervalo entre partos (dias) & $359 \pm 15$ & $390 \pm 13$ & 0,0533 \\
\hline Números de serviços por concepção & $1,2 \pm 0,4$ & $1,6 \pm 0,3$ & 0,1957 \\
\hline
\end{tabular}

${ }^{1}$ Novas = idade ao primeiro parto $<700 \mathrm{~d}$; Velhas $=$ idade ao primeiro parto $>700 \mathrm{~d}$

\section{CONCLUSÃO}

Novilhas que foram inseminadas aos 13 meses de idade e que pariram com IPP inferior a 700 dias, apresentaram menor produção de leite e componentes lácteos, que novilhas que foram inseminadas nos 15 meses e que pariram com IPP superior a 700 dias. Provavelmente devido às mais modestas e menos desafiadoras produções, novilhas inseminadas precocemente apresentaram melhor desempenho reprodutivo.

\section{REFERÊNCIAS}

CARDOSO, V.L.; NOGUEIRA, J.R.; VERCESI FILHO, A.E. Objetivos de seleção e valores econômicos de características de importância econômica para um sistema de produção de leite a pasto na região sudeste. Revista da Sociedade Brasileira de Zootecnia, v.33, p.320-327, 2004.

ETTEMA, J.F.; SANTOS, J.E.P. Impact of age at calving lactation, reproduction, health, and income in first-parity Holsteins on commercial farms. Journal of Dairy Science, v.87, p. 2730-2742, 2004.

HEINRICHS, A.J. Raising dairy replacements to meet the needs of the $21^{\text {st }}$ century. Journal of Dairy Science, v.76, p.3179-3187, 1993.

LEITE.T.E.; MORAES.J.C.F.; PIMENTEL.C.A. Eficiência produtiva e reprodutiva em vacas leiteiras. Ciência Rural, v.31, n.3, p.467-472, 2001.

NRC. Nutrient Requeriments of Dairy Cattle. 7.ed. National Academy Sciences, Washington:DC, 2001.
RIBEIRO.A.C.; McALLISTER.A.J.; QUEIROZ.S.A. Efeito das taxas de descarte sobre medidas econômicas de vacas leiteiras em kentucky. Revista Brasileira de Zootecnia, v.32, n.6, p.1737-1746, 2003.

SAS. SAS/STAT User's Guide. Versão 8.2. SAS Int. Inc., Cary:NC, 2001

SEJRSEN, K.; PURUP, S.; VESTERGAARD, M. High body weight gain and reduced bovine mammary growth: Physiological basis andimplications formilk yield potential. Domestic Animal Endocrinology, v.19, p.93-104, 2000.

TOZER, P.R.; HEINRICHS,A.J. What affects the costs of raising replacement dairy heifers: A multiplecomponent analysys? Journal of Dairy Science, v. 81, p. $1836-1844,2001$

VAN AMBURGH, M.E.; GALTON, D.M.; BAUMAN, D.E. Effects of three prepubertal body growth rates on performance of Holstein heifers during first lactation. Journal of Dairy Science, v.81, p.527-538, 1998.

VERCESI FILHO, A.E.;MADALENA, F.E.; FERREIRA, J.J. Pesos econômicos para seleção de gado de leite. Revista da Sociedade Brasileira de Zootecnia, v.29, p.145-152, 2000.

WOLFF, M.C.C.; MONARDES, H.G.; RIBAS, N.P. Fatores ambientais sobre a idade ao primeiro parto, dias abertos e intervalo entre partos em vacas da raça Holandesa na bacia leiteira de Castrolanda, estado do Paraná. Archives of Veterinary Science, v.9, n.2, p.35-41, 2004.

Recebido para publicação: 